${ }^{3}$ Royal College of Physicians and British Cardiac Society, fournal of the Royal College of Physicians of London, 1974/75, 9, 281.

' Cay, E L, et al, Therapy in Psychosomatic Medicine, 1977, 2, 534.

5 Evaluation of Comprehensive Rehabilitative and Preventive Programmes for Patients after Acute Myocardial Infarction. Copenhagen, WHO Regional Office for Europe, 1973.

${ }^{6}$ British Medical fournal, 1977, 1, 1306.

7 Cassem, N H, and Hackett, T P, Heart and Lung, 1973, 2, 382.

8 Skelton, M, and Dominian, J, British Medical fournal, 1973, 2, 101.

9 Mayou, R, Foster, A, and Williamson, B, British Medical fournal, 1978, 1, 699.

${ }^{10}$ Keith, R A, Fournal of Chronic Diseases, 1968, 21, 281.

11 Royal College of Physicians and British Cardiac Society, fournal of the Royal College of Physicians of London, 1975/76, 10, 213.
12 Eysenck, H J, and Eysenck, Sybil, B G, Manual of Eysenck Personality Inventory. London, University of London Press, 1972.

13 Fischer, S, Acta Cardiologica, 1970, suppl No 14, p 47.

14 Finlayson, A, and McEwan, J, Coronary Heart Disease and Patterns of Living, p 94. London, Croom Helm, 1977.

15 Mayou, R, Williamson, B, and Foster, A, British Medical fournal, 1976, 1,1577 .

16 Brewin, T B, British Medical fournal, 1977, 2, 1623.

17 Mayou, R, Foster, A, and Williamson, B, Fournal of Psychosomatic Research. In press.

18 Lancet, 1975, 2, 355.

\title{
Shortening hospital stay for psychiatric care: effect on patients and their families
}

\author{
S R HIRSCH, S PLATT, A KNIGHTS, A WEYMAN
}

British Medical fournal, 1979, 1, 442-446

\section{Summary and conclusions}

A one-year cohort of patients from a defined catchment area with acute functional disorders were allocated at random to brief care (experimental group) or standard care (control group) in hospital to examine the effect of shortening hospital stay on the clinical and social functioning of patients and the distress abnormal functioning caused to others. A total of 127 patients were interviewed on entry to the study, and 106 were followed up. The brief care group had significantly shorter mean and median lengths of stay than the control group, but there was no difference between the groups in the number of days spent in hospital during subsequent admissions. The groups were well matched for clinical and social variables. Rates of improvement over 13 weeks were essentially the same by all measures of outcome, including the Present State Examination and Patient's Behaviour Assessment Scale, which was developed for the study to measure deterioration in behaviour and social functioning and adverse effects and distress on others. There was no difference between the two groups in burden to the community supporting services, social security requirements, or GP attendances. Improvement rates were nearly identical on all measures within and across diagnostic subgroups. Brief care resulted in a $33 \%$ reduction in average length of stay compared with the year before but was associated with a corresponding increase in day hospital use. The short-stay policy continued the year after the study finished.

The findings confirm the value of shortening hospital stay and improving day care facilities for most localities.

Charing Cross Hospital and Medical School, London W6 8RF

S R HIRSCH, MPHIL, MRCP, professor of psychiatry

A KNIGHTS, MB, MRCPSYCH, lecturer in psychiatry

A WEYMAN, BSC(sOC), ACA, research sociologist

S PLATT, BA, MSC, research sociologist

\section{Introduction}

Economic pressures to reduce the number of beds for psychiatric care and shorten hospital stay are experienced worldwide, yet only two studies-both from the USA ${ }^{12}$ - have evaluated the effect of rapid discharge on patients' clinical and social functioning or the burden and distress it could cause their families. We have therefore examined this variable in a consecutive series of patients drawn from a catchment area population of 90000 admitted to a 38-bedded psychiatric unit in a district general hospital during 1975 . We report here the overall results.

\section{Patients and methods}

Immediately on admission patients were allocated at random to either brief care (short-stay group) or standard care (control group), those from outside the catchment area, aged under 16, or suffering from a diagnosable severe brain or physical disorder being excluded. Allocation was done the moment patients were admitted to avoid any possibility of bias. No restriction was put on standard care: patients were to be kept in hospital for as long as necessary. Patients in the brief care group and their families were told that the patient would probably be discharged in less than eight days. All the clinicians concerned agreed to make every effort to discharge patients within this time unless there were definite contraindications.

Each patient and his or her most affected relative or closest informant were assessed just after admission and again three months later to see if those in the brief care group had improved to the same extent as the controls. In all cases clinical symptoms during the previous four weeks were assessed by the MRC Present State Examination (PSE) five to seven days after admission. The PSE was repeated three months later. The patient's social behaviour and its effect on significant others were evaluated by interviewing the closest relative or informant 12-14 days and three months after admission. For this purpose we developed a semi-structured standardised interview-namely, the Patient's Behaviour Assessment Scale (PBAS) (later simplified and improved ${ }^{3 *}$ )-which provides ratings of the patient's behaviour-for example, withdrawal-and social performance-for example, working or engagement in leisure activities-and the adverse effects caused to the informant or others in the household, such as loss of leisure time or decrease in income. Furthermore, for each item of behaviour or social functioning that showed deterioration or absence of performance the interviewer asked whether the informant had experienced any distress or emotional burden; distress, however, was rated only if it was moderate or severe.

*The improved version of the PBAS-namely, the Social Behaviour Assessment Schedule (SBAS) - may be obtained from Professor S R Hirsch. 
SELECTION OF PATIENTS

During 1975, 304 patients were admitted to the psychiatric unit (fig 1). Of the 244 from the catchment area, 20 were excluded from the study because they were too young, physically ill, demented, or currently attending day hospital. Only 34 patients $(15 \%)$ were missed or excluded because of failure to obtain or complete an interview. Forty-five patients ( $20 \%$ of those assigned to one or other group) were excluded because they left hospital in less than four days, as we did not think that these patients would in any case be affected by the brief care policy; this was confirmed by the fact that similar proportions in each group stayed less than four days. Altogether 127 patients were interviewed on admission -70 assigned to brief care and 57 to standard care-and 106 were followed up.

Comparability of standard and brief care groups-The two groups were closely matched for all social and clinical variables examined (table I). There was also no significant difference between the groups in PSE scores or some 40 items of behaviour and social functioning measured on the PBAS for the period before admission.

\section{Results}

How successful were we in shortening the length of stay in the brief care group? Figure 2 plots the cumulative percentages of patients in the two groups discharged from hospital at various times

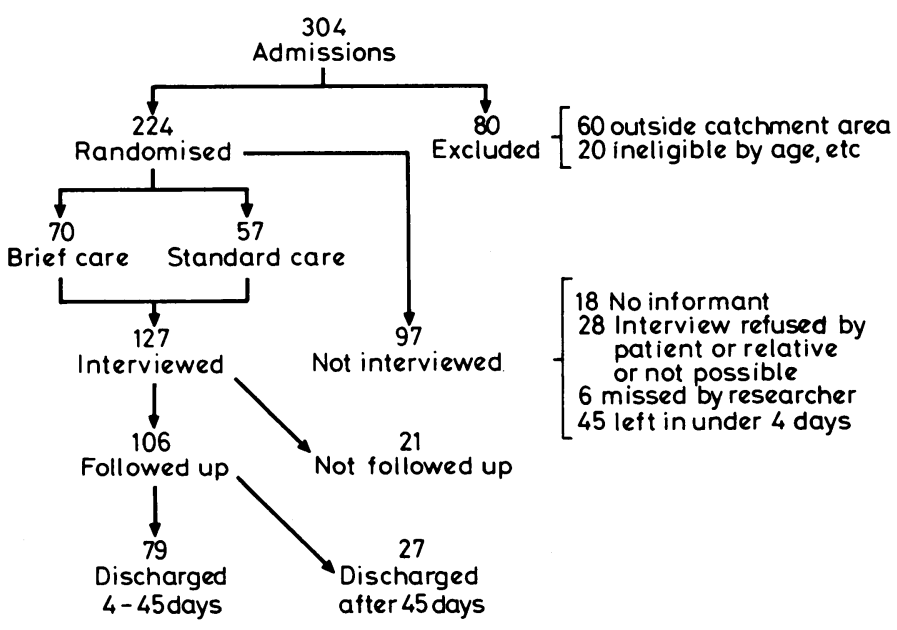

FIG 1-Constitution of cohort from all admissions to psychiatric unit during 1975.

TABLE I-Comparability of standard and brief care groups (patients interviewed at admission). Figures are percentages of patients

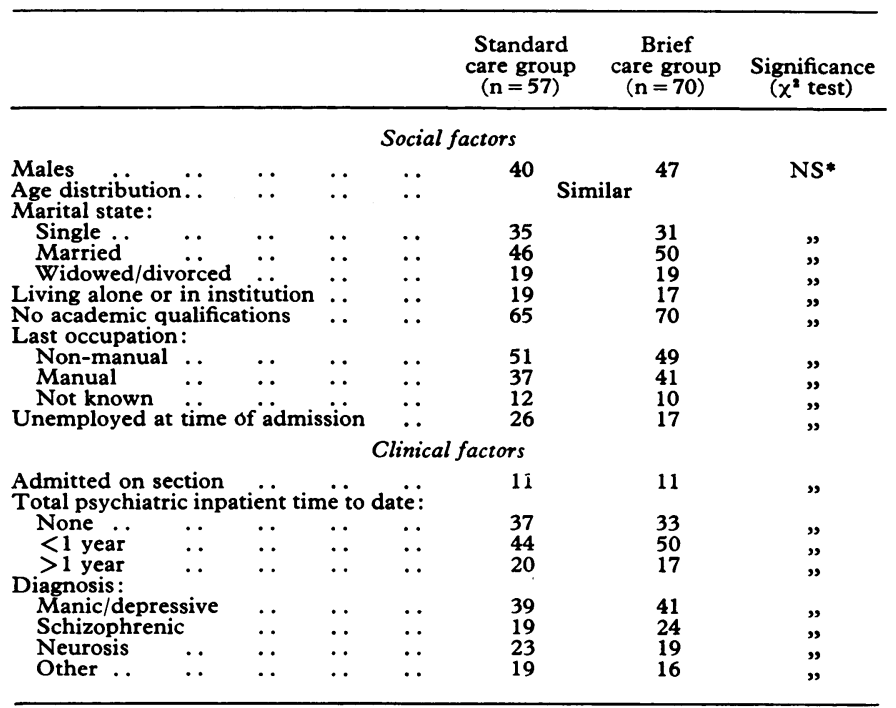

*NS = Not significant $(P \geqslant 0.05)$.

There was also a non-significant difference between groups in patients discharged before 45 days.

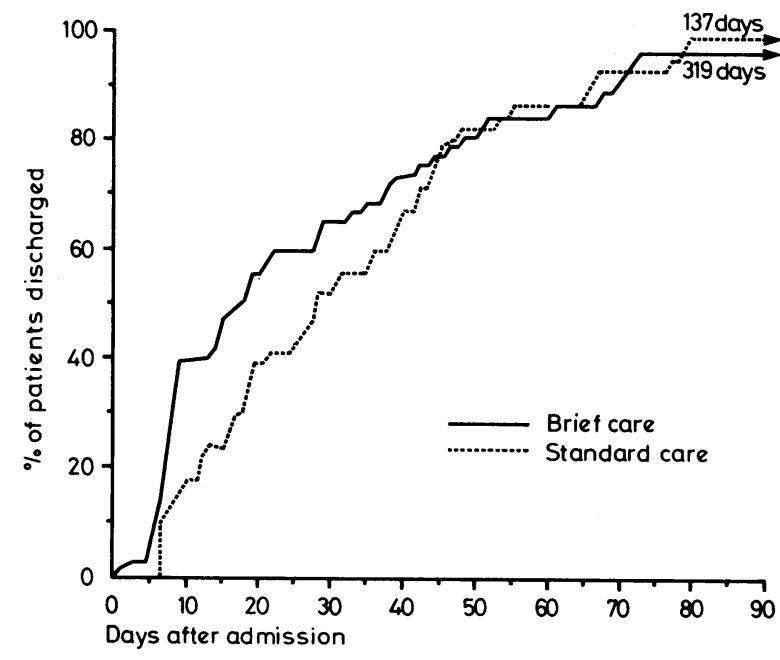

FIG 2-Cumulative percentages of patients in the two groups discharged at various times after admission. (Only the 106 patients followed up included.)

after admission. Only patients followed up are included, those who left hospital in under four days being excluded unless they had been transferred to the day hospital as a result of being assigned to brief care. At any point up to 45 days after admission a greater proportion of patients in the brief care group than the controls had been discharged from hospital. By 45 days, over $87 \%$ of the 127 interviewed patients had been discharged: after that point the brief care policy made no difference to the length of stay, equal proportions of both groups remaining in hospital more than 45 days. Thus this "target" group, which excluded patients leaving in under four or more than 45 days, provides the best basis for evaluating the effect of brief care on patients and their families.

Table II shows the results of the experimental procedure on mean and median lengths of stay in all 224 patients initially assigned to one or other group. Because of skew the median is a better measure of the difference between groups in length of stay. A significantly greater proportion of patients in the brief care group than the controls left hospital quickly, the median lengths of stay being 9 and 17 days respectively.

TABLE II-Analysis of inpatient stay of all 224 eligible patients initially assigned to standard or brief care

\begin{tabular}{|c|c|c|c|c|}
\hline & & $\begin{array}{l}\text { Standard } \\
\text { care group } \\
(\mathrm{n}=109)\end{array}$ & $\begin{array}{c}\text { Brief } \\
\text { care group } \\
(\mathbf{n}=115)\end{array}$ & Significance \\
\hline $\begin{array}{l}\text { Median stay (all patients; } n=224 \text { ) } \\
\text { Mean stay (all patients; } n=224 \text { ) } \\
\text { Mean stay }<45 \text { days (interviewed }\end{array}$ & $\because$. & $\begin{array}{l}17 \text { days } \\
28 \text { days }\end{array}$ & $\begin{array}{l}9 \text { days } \\
22 \text { days }\end{array}$ & $\stackrel{0.05}{\mathrm{NS}}$ \\
\hline $\begin{array}{l}\text { group; } n=99) . \\
\text { Proportion discharged within nine day }\end{array}$ & $\ddot{y}$ & 21 days & 16 days & 0.01 \\
\hline $\begin{array}{l}\text { (all patients; } n=224) \\
\text { Proportion readmitted in year after }\end{array}$ & . & $37(34 \%)$ & $62(54 \%)$ & 0.01 \\
\hline $\begin{array}{l}\text { discharge } \\
\text { Duration of inpatient stay during }\end{array}$ & . & $46(42 \%)$ & $39(34 \%)$ & NS \\
\hline $\begin{array}{l}\text { subsequent admission } \\
\text { Total stay during index admission }\end{array}$ & $\because$ & $\begin{array}{l}13 \cdot 8 \text { days } \\
3006 \text { days }\end{array}$ & $\begin{array}{l}13 \text { days } \\
2375^{*} \text { days }\end{array}$ & $\begin{array}{l}\text { NS } \\
\text { (631 days } \\
\text { saved) }\end{array}$ \\
\hline $\begin{array}{cccc}\text { Total stay during year from index } \\
\text { admission } & . . & . & \ldots\end{array}$ & . & 4508 days & $3840^{*}$ days & $\begin{array}{l}\text { (668 days } \\
\text { saved) }\end{array}$ \\
\hline
\end{tabular}

*Adjusted for difference in numbers.

\section{CLINICAL MEASURES OF OUTCOME}

A difference in length of stay for the target group having been established, the critical question is the effect on the patient's clinical and social functioning during the three months after admission and the impact of the patient's behaviour on significant others. Is there a disadvantage to brief hospitalisation? Table III gives the change in mental state based on PSE ratings for the month before and three months after admission in the 106 patients followed up. Details of how ratings are derived will be presented elsewhere. About $80 \%$ of the patients in each group were improved after three months, regard- 
TABLE III-Change in mental state from one month before to three months after admission in the 106 patients followed up. (Results based on PSE scores)

\begin{tabular}{llcccc}
\hline & & \multicolumn{3}{c}{ No $(\%)$ of patients: } \\
\cline { 3 - 6 } & & Improved & Unchanged & Worse \\
\hline Standard care group $(n=47)$ & $\ldots$ & $\ldots$ & $37(79)$ & $7(15)$ & $3(6)$ \\
Brief care group $(n=59)$ & $\ldots$ & $\ldots$ & $48(81)$ & $9(15)$ & $2(3)$
\end{tabular}

less of length of stay. Using subscores developed by Wing ${ }^{5}$ for totalling PSE scores for neurotic and psychotic symptoms, we found a negligible difference between groups in the proportion of patients whose scores improved for neurotic symptoms, or psychotic symptoms taken separately. As expected, psychotic symptoms improved less than neurotic symptoms, although there was a slight but nonsignificant advantage for patients in the brief care group in mean scores for neurotic and psychotic symptoms. Results were the same when comparisons were restricted to patients in the target group, for whom the difference in length of stay between brief and standard care was most pronounced, as when the calculations were based on all of the original 127 patients interviewed who were followed up after three months. Further comparisons (to be reported) failed to disclose any important significant difference between groups when broken down by diagnoses. Thus by all clinical indices patients in the brief care group did just as well clinically as those staying in hospital longer.

SOCIAL MEASURES OF OUTCOME

Figure 3 shows the change in mean PBAS scores of patients in the target group given brief and standard care. On each measure-that is, behaviour, social performance, and adverse effects on others-there was a dramatic (and significant) improvement in behaviour between that reported just before admission and that present at the time of interview two weeks later. Surprisingly, further significant improvement did not occur on any social measures between the two-week interview and follow-up after three months.

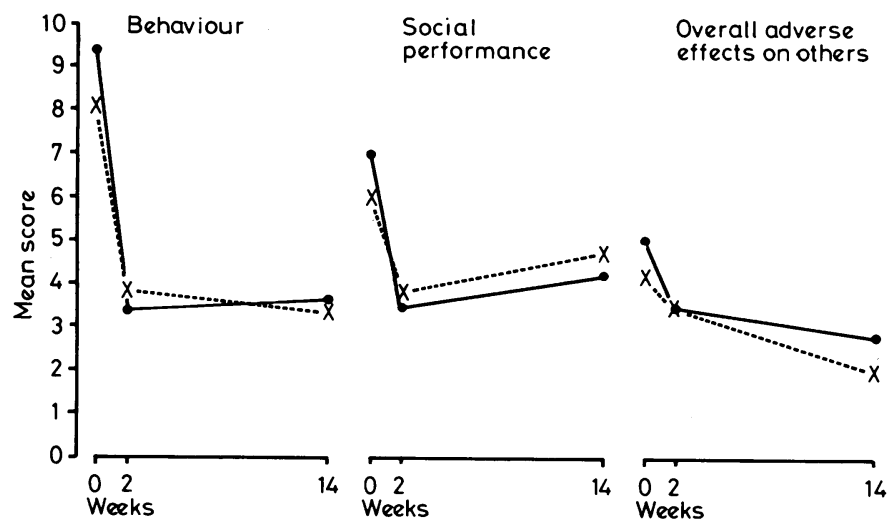

FIG 3-Change in mean PBAS scores of patients in target group (those discharged in 4-45 days) given brief $\left(\times \frac{\text { and standard ( }}{\times}\right.$ ) and care.

Interestingly, among all 224 eligible patients initially assigned to one or other group, $62(54 \%)$ of those given brief care compared with $37(34 \%)$ of the controls had been discharged five days or more before the two-week evaluation (see table II), yet the improvement in social functioning and rating of distress to the family was as good for the brief care families who already had the patients home as for the standard care group, in which most of the patients were still in hospital at the time of the first interview.

\section{DISTRESS TO RELATIVES}

Figure 4 shows the change in the informant's reported distress from the patient's behaviour, social performance, and adverse effects. There was neither a significant nor a noticeable difference between the

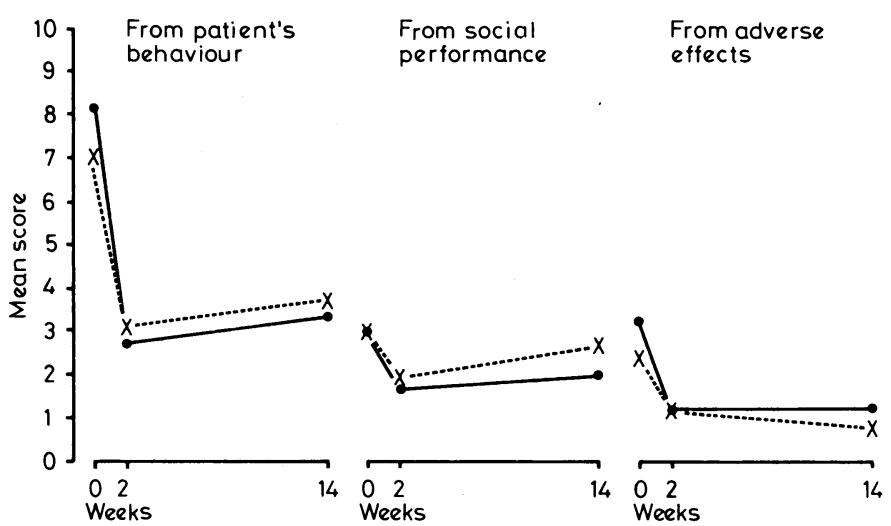

FIG 4-Change in mean PBAS scores in target group for informant's reported distress from patient's behaviour, social performance, and adverse effects. $\times \square$ Brief care group. -1 Standard care group.

brief and standard care groups. In general there were no important or consistent differences that favoured either group. This was true even after a covariant analysis, which took into account the small differences between the groups at the beginning of the study when comparing their scores at the end. Further analyses by diagnostic subgroup also failed to show any differences between brief and standard care.

\section{PROPORTION OF PATIENTS IMPROVING}

The proportion of patients improving varied considerably with what was being measured (table IV). The greatest improvement occurred in the informant's report of the patient's behaviour $(80 \%$ of all patients). Social performance showed the least improvement $(50 \%$ overall), and adverse effects to the informant fell somewhere in-between. Analysis of improvement in the informant's distress again showed that at follow-up the smallest proportion of relatives showed a resolution of distress owing to the patient's deteriorated social performance $(32 \%$ improved overall). There were no relevant significant differences between the brief and standard care groups in the proportions of patients showing improvement. More-detailed tables would disclose some differences between the groups without any consistent trend favouring either.

TABLE IV-Overall improvement over three months in all social measures combined (informant's report) and in distress to informant. Results based on total PBAS scores

\begin{tabular}{|c|c|c|c|c|c|}
\hline & & \multirow{2}{*}{$\begin{array}{l}\text { No of } \\
\text { cases* }\end{array}$} & \multicolumn{2}{|c|}{$\%$ improved } & \multirow{2}{*}{ Significance } \\
\hline & & & $\begin{array}{l}\text { Standard } \\
\text { care group }\end{array}$ & $\begin{array}{c}\text { Brief } \\
\text { care group }\end{array}$ & \\
\hline \multicolumn{6}{|c|}{ Social measures } \\
\hline $\begin{array}{l}\text { Behaviour } \\
\text { Social performance } \\
\text { Adverse effects on: }\end{array}$ & $\begin{array}{l}\cdots \\
\cdots\end{array}$ & $\begin{array}{l}105 \\
105\end{array}$ & $\begin{array}{l}76 \\
55\end{array}$ & $\begin{array}{l}83 \\
47\end{array}$ & $\begin{array}{l}\text { NS } \\
"\end{array}$ \\
\hline $\begin{array}{ll}\text { Children } & \ldots \\
\text { Informant } & \ldots \\
\text { All adults } & \ldots\end{array}$ & 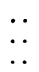 & $\begin{array}{l}17 \\
89 \\
98\end{array}$ & $\begin{array}{r}100 \\
68 \\
65\end{array}$ & $\begin{array}{l}90 \\
76 \\
69\end{array}$ & ", \\
\hline \multicolumn{6}{|c|}{ Informant's distress } \\
\hline $\begin{array}{l}\text { Behaviour } \\
\text { Social performance } \\
\text { Adverse effects .. }\end{array}$ & $\begin{array}{l}\ldots \\
\cdots\end{array}$ & $\begin{array}{r}100 \\
78 \\
63\end{array}$ & $\begin{array}{l}82 \\
27 \\
48\end{array}$ & $\begin{array}{l}70 \\
37 \\
47\end{array}$ & "; \\
\hline
\end{tabular}

*Patient not included if no abnormality appeared.

NS = Not significant $(P \geqslant 0.05)$

\section{EFFECT ON COMMUNITY RESOURCES}

We have shown that neither the patients nor their families suffered when hospital stay was shortened; however, a question remains concerning resources: Did the brief care group consume more hospital or community resources than the standard care group ? Was the hospital saving in the short term lost in the long term because of longer or more frequent subsequent admissions?

There was no difference between the two groups in the number of days spent in hospital during a year from the brief admission (table 
II). Nevertheless, patients in the brief care group stayed a total of 631 days less in hospital during their brief admission than the controls, a saving of $21 \%$. Comparison of the numbers of days spent in hospital over a year from day one of the index admission showed a saving of 668 days $(15 \%)$ in the brief care group. Compared with the controls more patients in the brief care group were discharged in under nine days and fewer readmitted in the year after discharge. The number of subsequent days spent as an inpatient was the same $(13+)$ for both groups.

\section{EFFECT ON SUPPORTING SERVICES}

An analysis was made from carefully collected data of the effect of brief care on other services (findings to be published elsewhere; all tests failed to reach $5 \%$ level of significance). The effect of applying a short-stay policy did not lead to differences in the number of outpatient attendances during the year from the first day of admission or to an increase in the number of attendances to the general practitioner. The groups did not differ in the number of local social service attendances or amount of social security benefits received by the patients and their families. While in hospital, and subsequently, there was no difference in the number of patients who saw the hospital social worker or the number of hours spent in contact with the hospital social worker.

\section{DAY HOSPITAL USE AS ADJUNCT TO BRIEF CARE}

The only service of which the brief care group made significantly more use was the day hospital. Owing to an unexplained error the attendance records of the day hospital covering half the period of this study were destroyed. An estimate based on extrapolation from six months' data, however, suggests that the expected number of excess days spent in the day hospital by patients in the brief care group over a year beginning with the index admission was 523, which nearly makes up for the 668 inpatient days saved during the same period. "Brief care" in this study really means shortening inpatient stay and replacing it with day-patient care for about half the patients; $47 \%$ of patients in the brief care group with stays less than 45 days were admitted to the day hospital at some time during the year compared with $34 \%$ of the controls.

\section{Discussion}

\section{CAN LENGTH OF STAY BE SHORTENED REALISTICALLY?}

Is it realistic to expect clinicians to change their habits when the pressure is off, the research team has disappeared, and there is no pressure from the research team to discharge patients quickly? Table $\mathrm{V}$ shows that the decrease over the year before in the mean and median numbers of days spent as an inpatient in the standard and brief care groups combined during the study year (1975) was maintained in 1976 after the research team had gone. A significant decrease in the length of stay was maintained, although it was not as great a reduction as the brief care group had achieved in 1975 (see table II).

TABLE $\mathrm{v}-$ Mean and median lengths of inpatient stay (days) during 1974, 1975 (brief and standard care groups combined), and 1976

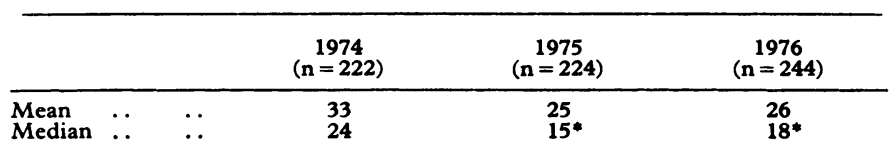

*Significantly different from 1974 value $(P<0.01)$

\section{ECONOMIC SAVINGS}

A better way to calculate the economic savings possible from brief care is to compare the length of stay in the brief care group during the study year with the length of stay of all catchment area inpatients during the year before. The mean number of days fell from 33 for all admissions in 1974 to 22 for patients given brief care in 1975 , an overall saving of $33 \%$. From the point of view of the number of patients affected the saving was even greater, because the median stay fell from 24 days to 9 , a reduction of $63 \%$. Thus the savings that result from brief care could be substantial.

From the point of view of testing the effects on patients and relatives, however, though we achieved a significant difference between the groups in lengths of stay, it could be argued that an eight-day difference in median lengths of stay between the standard and brief care groups is clinically not very great; our standard care group would be thought by some to have had relatively brief care as well. The difference of only eight days in median stay is due to a halo effect; standard care was five days shorter during the study year than the year before. It could be argued that standard care would have come out better if the patients had had a chance to stay in hospital longer.

Our results replicate those of a closely similar study carried out in New York City by Herz et al, ${ }^{2}$ which were published during the time our data were being collected. Though they used different instruments and excluded patients who could not return to families, as well as those with alcoholism or psychopathy (so that they had more schizophrenics in their sample), the variables they measured, the strategy of their research, and their results were closely similar to ours.

The median stay of their brief care groups was 8 days and the mean 11; our brief care group had a median stay of 9 days and a mean stay of 22. Patients in their standard care groups, however, had a median stay of 28 days and mean stay of 60 , which were much longer than in our series (median stay 17 days, mean 28). Because our results are otherwise so similar we think that we can reasonably look to their study for an indication of the benefits of keeping patients considerably longer in hospital. Herz et al used variables analogous to the ones we examined, and their follow-up period was extended to two years. At no time after admission did they find any sizable or significant difference in social or clinical outcome or in the effect on the patient's family between the brief and standard care groups. This confirms our finding that there is no advantage to prolonged hospitalisation; in their study, standard care was much more prolonged.

Given this replication of findings and the additional comparison for the group having prolonged hospitalisation that the study of Herz et al offers, we conclude that a general policy of brief hospitalisation that allows for clinical discretion to keep selected patients in hospital as long as necessary offers no discernible disadvantage to psychiatric patients. On the contrary, both our findings and those in New York support the view that the major benefit of hospitalisation was during the first two weeks, when the most dramatic reduction in clinical symptoms and the major improvement in social performance took place, as well as a reduction in distress experienced by the family. Given current standards and practices, which we believe are reflected in our study, the reduction in inpatient beds would need to be matched by a corresponding increase in day places, at least in the first instance.

Herz et al reported a significantly better record of return to work for patients given brief care than those given standard care within the group that could be expected to be re-employed. Though we have not yet done this analysis, we conclude, contrary to what might have been expected, that the effects of a brief care policy, if anything, appear to be beneficial to the patient and family, not to mention those who have a fiscal concern for the health of the NHS. Our study complements one by Jones and Goldberg in Manchester, ${ }^{\circ}$ who recorded a shorter stay in hospital, better record of return to work, and considerable economic benefit to the patient and the community for patients treated in a psychiatric unit based in a district general hospital as compared with one based in a mental hospital. Taking our study with theirs should provide encouragement for those who are considering the cost and benefits of rapid discharge and community-based psychiatric facilities, even after considering the benefit from many points of view. 
Our deepest thanks are owed to the medical and nursing staff of the unit where this study was carried out, who so generously enabled the work to succeed. In particular we thank Drs Sylvia Blunden, Hugh Baker, Alan Black, Stephen Frank, and Peter Dally. Thanks are due to Leonie Cox, who met the secretarial and organisational needs of the project; Professor John Wing, who provided the computer analysis of the PSE data; and Ken MacRae, who provided statistical advice and computer facilities at Charing Cross Medical School. The study was supported by a grant from the DHSS.

Requests for reprints and copies of the Social Behaviour Assessment Schedule should be addressed to: Professor S R Hirsch, Department of Psychiatry, Charing Cross Hospital, Fulham Palace Road, London W6 8RF.

\section{References}

1 Glick, I D, Hargreaves, W A, and Goldfield, W N, Archives of General Psychiatry, 1974, 30, 3630.

${ }^{2}$ Herz, M I, Endicott, J, and Spitzer, K L, American fournal of Psychiatry, 1977, 134, 502.

${ }^{3}$ Platt, S, et al, Social Behaviour Assessment Schedule (SBAS). I : Development and Contents of a New Interview Schedule. Submitted for publication.

Platt, S, et al, Social Behaviour Assessment Schedule (SBAS). II : Reliability of a New Interview Schedule. To be published.

5 Wing, J, personal communication.

6 Jones, R J, and Goldberg, D. To be published.

(Accepted 27 November 1978)

\title{
Gentamicin- and silver-resistant pseudomonas in a burns unit
}

\author{
K BRIDGES, A KIDSON, E J L LOWBURY, M D WILKINS
}

British Medical fournal, 1979, 1, 446-449

\section{Summary and conclusions}

In 1977-8 gentamicin-resistant strains of Pseudomonas aeruginosa became very common in a burns unit, over $90 \%$ being resistant at the peak of the outbreak. Some strains were also resistant to silver nitrate, though silver resistance was not found in any other strains of Ps aeruginosa isolated. Unlike the gentamicin resistance, the silver resistance was unstable, and strains became sensitive on repeated subculture. All the gentamicinresistant strains of $P s$ aeruginosa were of the same serotype (O:11, H:2,5). Though gentamicin resistance could be transferred in vitro from resistant strains of Ps aeruginosa to one sensitive strain of Ps aeruginosa, there was no evidence of in-vivo transfer of gentamicin resistance between strains of pseudomonas in the patients' burns, nor was there evidence of transfer of gentamicin resistance between Ps aeruginosa and enterobacteria. Carbenicillin-resistant and gentamicin-resistant Ps aeruginosa were sometimes found in the same burns, but no gentamicin-carbenicillin (doubly) resistant strains were found among the 986 strains tested during the outbreak.

The outbreak of gentamicin-resistant Ps aeruginosa from burns was not reduced by stopping treatment with gentamicin and its analogues but only by segregating all patients with Ps aeruginosa in one of the two wards of the unit and admitting new patients only to the other ward.

\section{Introduction}

Systemic gentamicin and topical silver preparations have been used in this unit since the mid-1960s. For most of that period few strains of Pseudomonas aeruginosa isolated from the patients'

\footnotetext{
MRC Burns and Industrial Injuries Unit, Birmingham Accident Hospital, Birmingham

K BRIDGES, BSC, microbiologist

A KIDSON, FIMIs, chief medical laboratory scientist

E J L LOWBURY, DM, FRCP, bacteriologist, visiting professor of medical microbiology, University of Aston, Birmingham

M D WILKINS, FIMLS, senior research officer
}

burns have been resistant to gentamicin and none have been resistant to silver. ${ }^{-3}$ In 1977 , however, gentamicin resistance became very common, and the resistant strains were often also resistant to silver nitrate. Since gentamicin (and its analogues) and silver preparations are probably the most effective of the few agents available for, respectively, systemic treatment and topical prophylaxis against pseudomonal infections, the emergence of these resistant variants posed a serious threat to controlling infection in the unit.

We describe here the emergence of these resistant variants and our measures to eliminate them. We also describe in-vitro tests for transfer of resistance.

\section{Incidence and control of resistance}

METHODS

Burns were examined for bacterial flora when patients were admitted to the unit, at all changes of dressings, at operations, and daily if the burns were exposed, by methods described elsewhere. ${ }^{2}$ Ps aeruginosa, Escherichia coli, Klebsiella spp, Enterobacter spp, Proteus spp, and other Gram-negative bacilli were identified by standard methods. ${ }^{4}$ All isolates of Gram-negative bacilli were tested for sensitivity to gentamicin, amikacin, carbenicillin, neomycin, trimethoprim, and sulphadiazine by a ditch-plate diffusion test. ${ }^{5}$ Tube dilution tests were also made on some of the strains, using nutrient broth as the culture medium, with 1 drop $(0.02 \mathrm{ml})$ of a $1 / 1000$ dilution of an overnight broth culture as the inoculum. In the ditchplate test for gentamicin sensitivity two dilutions were used, one containing $50 \mathrm{mg} / \mathrm{l}$ and one containing $10 \mathrm{mg} / \mathrm{l}$ of gentaruicin sulphate in the nutrient agar of the ditch. Strains were considered sensitive if the minimal inhibitory concentration (MIC) of gentamicin was $8 \mathrm{mg} / \mathrm{l}$ or less. All strains which were gentamicin-sensitive by the tube dilution test showed zones of inhibition in the ditch-plate diffusion test which were closely similar to that obtained with the sensitive control strain (MIC $2 \mathrm{mg} / \mathrm{l}$ ) tested on the same plate; resistant strains, which had MICs of $16-32 \mathrm{mg} / \mathrm{l}$, grew across the agar of the ditch containing $10 \mathrm{mg} / \mathrm{l}$ gentamicin.

Tests for silver nitrate resistance were performed as described by Cason et al, ${ }^{6}$ using a plate dilution method with serial dilutions of silver nitrate in nutrient agar.

\section{Results}

Gentamicin-resistant $P s$ aeruginosa

Table I shows the proportion of gentamicin-resistant strains of Ps aeruginosa isolated from burns from June 1977 to September 1978 Each patient had one or more burns, and each burn colonised by 